\title{
Manipulación, censura e imagen de autor en la nueva edición de los Diarios de Alejandra Pizarnik
}

\section{Manipulation, Censorship and Author's Image in the New Edition of Alejandra Pizarnik's Journals}

\author{
Cristina Piña \\ Universidad de Mar del Plata, Argentina
}

Resumen: La comparación entre la nueva edición ampliada de 2013 de los Diarios de Pizarnik, la primera edición de 2003 y los originales depositados en la Biblioteca de Princeton revela, por un lado, las manipulaciones a que la editora Ana Becciú sometió el material en la primera edición y las exclusiones realizadas en la segunda; por el otro, la autocensura aplicada por la propia Pizarnik a las reescrituras de los fragmentos de los diarios de París que publicó en vida. Como consecuencia, se perfilan diferentes figuras de autor y su corpus literario confirma su condición de objeto en constante mutación.

Palabras clave: diarios, manipulación, exclusiones, censura, autocensura, figura de autor.

Abstract: The comparison among the 2013 new enlarged edition of Alejandra Pizarnik's Diarios, the first 2003 edition, and the Pizarnik Papers kept at the Princeton Library discloses, on the one hand, the manipulations practiced by the editor Ana Becciú on the originals when editing the first edition, as well as the things she excluded in the case of the second one. On the other hand, Pizarnik's self-censorship is revealed in the fragments she rewrote of the Paris journals and published while she was still alive. As a consequence, we can find different author's figures and Pizarnik's oeuvre confirms itself as a constantly changing object. Keywords: Diaries, Manipulation, Exclusions, Censorship, Self-censorship, Author's figure. 
Cuidame, Señor, de mis amigos, que de mis enemigos me cuido yo

REFRÁN POPULAR ESPAÑOL

$\mathrm{E}_{\mathrm{p}}^{\mathrm{n}}$

n noviembre de 2013, casi sin advertencias ni propaganda previa, apareció en la editorial Lumen de Barcelona una nueva edición de los Diarios de Alejandra Pizarnik, realizada una vez más por Ana Becciú, exactamente diez años después de la primera. Además del lógico interés que despierta cualquier publicación de material inédito de la autora, en este caso su lectura resultaba significativa en especial para comprobar qué repercusión habían tenido en esta reedición ampliada las críticas que recibió la primera edición.

De entre éstas, cabe citar la de Ana Nuño - prologuista de la erróneamente llamada Prosa completa de Pizarnik de la misma editorial y editora- quien, en su reseña para el diario La vanguardia, puso en entredicho los criterios editoriales de Becciú (Nuño, 2004: 3); la de Patricia Venti, de corte académico, quien señaló que faltaban 139 entradas además de otros defectos (Venti, 2004: 1), y la mía, que se centraba en la supuesta condición de "diario de escritora" que le atribuye Becciú a su edición, al estilo del que Leonard Woolf realizó con el de Virginia (Piña, 2007). En ese artículo, se partía de la confrontación con los fragmentos que la propia editora había publicado -conjuntamente con Olga Orozco- en Alejandra Pizarnik. A Profile, editado por Frank Graziano y luego publicado en castellano bajo el título de Semblanza por el Fondo de Cultura Económica. En estos fragmentos aparecían afirmaciones de la 
importancia de: "En el fondo yo odio la poesía. Es, para mí, una condena a la abstracción” (Graziano, 1987: 271), que luego Becciú excluyó de su versión de los Diarios (Piña, 2007: 71-72). ${ }^{1}$

El mero tamaño de la nueva edición parecía demostrar que las críticas no habían caído en saco roto y por fin contábamos con los diarios completos: frente a las 504 páginas de la primera, en ésta nos encontramos nada menos que con 1102, en las cuales, además, se enmienda una de las intervenciones realizadas por Becciú en la primera edición. En efecto, allí la editora informaba que había mezclado, a partir de su propio criterio -que no explicaba ni fundamentaba-, las tres versiones existentes del diario parisino -el "texto previo" y las dos reescrituras-, según se ve en esta cita del prólogo:

Mi opción ha sido no prescindir del texto previo; pero, en los casos de aquellas anotaciones para las que existe la versión resumida y corregida por Pizarnik, me he inclinado por ella, y he incorporado en su totalidad el texto de los legajos, que en el presente libro aparecen en cursiva, respetando las fechas que allí figuran, aunque en muchos casos no coincidan con las del texto previo (Pizarnik, 2003: 8-9).

El resultado, como puede verse a partir de esta nueva edición, accidental o deliberadamente contribuía a construir una determinada imagen de la autora, imagen que en ciertas ocasiones respe-

${ }^{1}$ Es realmente una pena que la edición de 2013 haya aparecido casi conjuntamente con la entrada en prensa del libro de Mariana Di Ció Une calligraphie des ombres. Les manuscrits d'Alejandra Pizarnik. Di Ció es sin duda quien ha trabajado de manera más sistemática y productiva los manuscritos de la poeta, y las páginas que le dedica a sus diarios, pese a no ser demasiadas, son ineludibles y de singular valor a la hora de definir la naturaleza de los veintiún cuadernos que constituyen el "Diario Pizarnik". En una nota (Di Ció, 2014: 52), la autora por un lado sintetiza y por el otro amplía las objeciones que la crítica ha hecho a la edición de Becciú de 2003. 
taba su autocensura - porque en las reescrituras con miras a publicación de fragmentos de su diario, Pizarnik convertía relaciones homosexuales en heterosexuales- $y$ en otras soslayaba hechos dolorosos, como el aborto al que se sometió la poeta en París y la identidad del responsable, quien la sobrevivió muchos años.

Pero también en esta nueva versión se separan, por un lado, lo que podríamos llamar los "cuadernos centrales" del diario veinte en total según la editora, aunque en rigor serían veintiuno contando la libreta-agenda de algunos meses de 1970 y 1972 que Becciú informa haber descartado (Princeton, Box 3 Folder 1) - y que resultan de singular crudeza, ${ }^{2}$ de los seis Apéndices donde se presentan materiales de diferentes características, por el otro. Así, se incluyen las reescrituras que en su momento hiciera la autora de partes de ellos - a veces publicadas, a veces no- y entre las que se encuentran las que acabo de mencionar del período parisino, tanto como páginas sueltas o legajos de diversos años organizados por temas o por fechas.

Entre ellos merecen especial atención dos grupos, en razón de los interrogantes que nos plantean de entrada: las doce hojas encarpetadas bajo el título Les Tiroirs de l'hiver-que aparecieron publicadas en La Nouvelle Revue Française- ${ }^{3}$ y las cuarenta y ocho hojas mecanografiadas puestas dentro de un sobre donde la propia Pizarnik escribió: Journal de Châtenay-Malabry, 1960-1961, es decir, el lugar y período en el que vivió en la casa suburbana de sus

${ }^{2}$ Los califico así porque la autora se refiere tanto a sí misma como a personas de su familia, de su círculo más íntimo de amigos y de sus amantes con singular brutalidad y relata experiencias sexuales y cercanas a la locura sin ahorrar detalles.

${ }^{3}$ Para las coincidencias y diferencias entre las versiones del diario publicadas en español en la revista Mito y en francés en La Nouvelle Révue Française me he remitido al artículo de Patricio Ferrari (todavía inédito) citado en la bibliografía. 
tíos Simon y Dvoira Pozarnik. ${ }^{4}$ Ambos materiales supuestamente se habrían hallado en el domicilio de Olga Orozco después de que se publicara la primera edición de 2003. Si digo "supuestamente" es por dos motivos: ante todo, porque Orozco murió en 1999 y, como Becciú fue una de sus albaceas, llama la atención que llevara tantos ańos encontrar los textos de Pizarnik entre los papeles de la poeta pampeana. En segundo lugar, porque una de las entradas del Journal -el que abarca 19 textos escritos entre el 24 de abril y el 7 de agosto de 1960- ya aparecía parcialmente en la primera edición. Me refiero a la del 4 de junio de 1961, cuyos cuatro primeros párrafos pueden leerse en las páginas 165-166 de la edición del 2003, mientras que en la de 2013 los nueve párrafos de la entrada entera ocupan las páginas 328-330. Esto nos lleva a preguntarnos ¿de dónde surgió esa cita si el hallazgo del Journal todavía no se había producido...?

Es decir que, cuando leemos atentamente esta nueva edición y la confrontamos tanto con la primera como con los fragmentos aparecidos en el libro de Graziano y la versión completa depositada en la Biblioteca de la Universidad de Princeton - a la que he tenido acceso primero gracias a dos colegas estudiosos de Pizarnik, los doctores Patricia Venti y Patricio Ferrari, quienes me facilitaron hace tiempo lo que recogieron en sus respectivas estadías allí y después a través mi propia visita a Princeton en septiembre de 2015-, nos encontramos con una serie de cuestiones, interrogantes y problemas en los que me centraré en el presente trabajo.

Ante todo, me detendré en el tipo de material excluido de la última edición, la cual, pese a su tamaño, no está completa; en segundo término, en el tipo de recortes realizados por la editora en

${ }^{4}$ El apellido es de origen ruso y se transliteraría como Posharnik, del cual surge el Pozarnik de la familia que quedó en Francia. En Argentina, la transformación de "o" en " $i$ " seguramente se produjo debido la escasa costumbre de los empleados de Migraciones a apellidos centroeuropeos. 
la versión anterior, lo que nos lleva a desestimar su afirmación de que se proponía hacer un "diario de escritora". En rigor, como procederé a demostrarlo, esa primera edición de los Diarios parecería tener como una de sus metas - consciente o inconsciente- darnos una determinada imagen de Pizarnik, una figuración autoral en gran medida construida por la editora. En tercer término, en la evaluación de los defectos de la actual edición, los cuales, como veremos, no sólo agravan algunos de la edición anterior a partir del manejo de las notas y la información relativa al origen de los nuevos materiales incluidos, sino que suma fallas que especificaré. Por fin, me centraré con más detalle tanto en la imagen de escritora ${ }^{5}$ que ambas ediciones aspiran a darnos - sea por parte de la autora o de la editora-, como dejar en claro el tipo de manipulaciones a las que se sometieron los textos para lograr cada una de ellas. ${ }^{6}$

\section{Entre el pudor y la negligencia}

A la hora de evaluar el tipo de materiales excluidos de la nueva edición, personalmente oscilo entre la coincidencia y el asombro. En efecto, cuando analizamos el principio de exclusión practicado por la editora, advertimos que, en primer término, ha dejado de lado fragmentos especialmente dolorosos y terribles concernientes a los sentimientos negativos de la poeta hacia su madre, su padre y su familia en general. Acerca de esta decisión, no puedo sino compartirla -contradiciendo así a uno de los críticos más destacados

${ }^{5}$ Utilizo alternativamente las expresiones figuración autoral, imagen de escritor, autofiguración y figura de autor según las denominaciones de los ensayistas que se han ocupado de ella, que especificaré en detalle cuando lleguemos a la parte centrada en dicha cuestión.

${ }^{6}$ Señalo que además de los artículos y libros que citaré hay otros sumamente importantes centrados en los Diarios de Pizarnik que figurarán en la bibliografía, si bien no se ocupan de los aspectos que aquí destaco. Se trata de los de Patricia Venti, Federica Rocco, Carolina Vrech y Núria Calafell Sala. 
del siglo XX, Maurice Blanchot, quien afirma que todo lo escrito está destinado a publicarse, al margen de la voluntad de edición del autor (Blanchot, 1992: 260)-, en razón de que nada agregan a lo que ya se había revelado de las difíciles relaciones familiares de la escritora y, sobre todo, entran en una zona de extrema y desgarradora intimidad que, desde mi punto de vista, poco aporta a la comprensión de su obra. Por este motivo no voy a citar ninguno de tales fragmentos.

Pero, asimismo, se han cercenado partes que, lejos de resultar ofensivas o perjudiciales, revisten singular interés, en tanto nos dan una idea de los gustos musicales de Pizarnik, tema casi desconocido para sus lectores, si exceptuamos las dispersas referencias al blues, a Ute Lemperer y Janice Joplin que encontramos en su obra. Como ejemplo, cito esta mención, que aparece después de uno de los pocos comentarios musicales transcriptos en la segunda edición, relativo a un ballet sobre la $7^{a}$ sinfonía de Beethoven que Alejandra había visto en televisión. La editora inexplicablemente excluye estos dos párrafos, el segundo de los cuales nos lleva, además, al ámbito de sus gustos en pintura:

Dato: en Córdoba, cierta noche, en el jardín, escuchábamos la $7^{a}$ de Bet. Ese día yo "estaba de turno" para dar vuelta a la manivela del gramófono. Recuerdo que, ensimismada en la música, la solté y me lastimé terriblemente la mano...

Miro una reproducción de Van Gogh. Al pie leo la firma: Vincent. Me dan ganas de llorar. Es como si estaría $[s i c]$ pidiendo perdón por existir! Vincent! Nada más!?

En otro sentido, y también sin explicación alguna, la editora ha eliminado de esta edición ciertas referencias a la bisexualidad

${ }^{7}$ Debo esta cita al material facilitado por el Dr. Patricio Ferrari. Box 1, Folder 3: Fecha 26 de Julio de 1955. 
de la escritora, que sin embargo se hace claramente explícita en numerosas entradas. A pesar de ello, se descartan párrafos como los siguientes, aunque se hayan incluido múltiples referencias a su relación erótica con Elizabeth Azcona Cranwell y con diversos hombres:

La relación con Elizabeth es complejísima. Mina se fue a Francia, y yo creo que E. está conmigo y se me queja de su abandono para que le sirva después como testigo ante Mina de que ella nunca la olvidó.

Ayer hice el amor con Augusto L. Cuando se fue quedé tranquila y dichosa, y me dije "después de tanta metafísica he aquí lo que importa” [...] Fue más intenso que lo de Enrique Molina y no sé por qué los asocio tanto. ${ }^{8}$

Para quien no haya leído esta segunda edición, destaco que aparecen numerosas y detalladas referencias a la relación sexual de Alejandra con Enrique Molina -silenciada, en cambio, en la primera, a pesar de que el autor había muerto en 1997, aunque dicho silencio podría entenderse por respeto a su viuda- lo que hace menos comprensible la exclusión de la entrada precedente.

Existen muchas más supresiones que merecerían señalarse pero, debido a que hay otros aspectos por considerar, he recalcado las intervenciones anteriores a fin de subrayar la arbitrariedad de la selección, en especial porque la editora en ningún momento hace explícitos los criterios sobre los que se ha apoyado para exclusiones de carácter tan dispar.

\section{Una do li trua de la limentuá...}

${ }^{8}$ Estas dos citas las debo al material facilitado por la Dra. Patricia Venti. La primera es de Box 1, Folder 7. Fecha 8 de marzo de 1959; la segunda, Box 1, Folder 8. Fecha 25 de diciembre, 1960 
Algunos lectores sin duda recordarán la cantinela infantil con la que acompañábamos las elecciones azarosas y que he tomado para introducir el segundo punto de mi trabajo: la demostración de que la primera edición de los Diarios no tenía que ver con extraer un "diario de escritora" del diario personal de la poeta. Porque si Becciú realmente hubiera cumplido con el deseo que Alejandra le manifestó, según dice en las primeras frases de la "Introducción" a la edición de 2003 de los Diarios, no nos encontraríamos con la sucesión de interrogantes que nos asaltan:

Para la presente edición me he guiado por el deseo de Alejandra Pizarnik, expresado verbalmente en la tarde del domingo 24 de septiembre de 1972, cuando fui a visitarla a su casa de la calle Montevideo 980. [...] [E]n un momento dado, refriéndose a sus diarios, dijo que había estado pensando en que le gustaría que se hiciera una selección para publicarla un día como un "diario de escritora" (Pizarnik, 2003: 7).

Si efectivamente hubiera querido hacer un diario de escritora, ¿cómo se explica, por un lado, que la editora recogiera tantas referencias personales, sexuales y familiares y, por otro, que excluyera las consideraciones de Pizarnik sobre una gran cantidad de autores? Entre ellos cito a García Lorca -a quien afirma "adorar" en agosto de 1955- (Pizarnik, 2013: 141), al igual que a Unamuno o Leopardi (169); William Faulkner y Albert Camus (266); Henry Miller (330) y, para no convertir esto en una guía de la literatura del siglo XX, a dos autores cuya exclusión resulta especialmente enigmática: Gabriel García Márquez y Djuna Barnes.

Del primero, Alejandra emite una opinión elogiosa, como se advierte en esta entrada del 22 de agosto de 1968: 
El libro de G. Márquez ${ }^{9}$ no me permite ocuparme de otra cosa. Me absorbe íntegramente. Pocas veces he envidiado tanto a un escritor como a él. Escribe lejos, muy lejos, de toda introspección y no obstante, ha de hacerle bien. No es para menos: funda un pueblo con todo lo que se necesita para un pueblo y luego lo deshace porque tiene ganas. Pero más que nada le envidio su lenguaje (un hijo de inmigrantes judíos no podría escribir así) tan flexible y poético, tan innato y tan limitado a sus proyectos (Pizarnik, 2013: 811).

Por lo tanto, sólo podríamos explicar su exclusión a partir de hipotéticos prejuicios de la editora -para cierta parte de los intelectuales argentinos, García Márquez carece de valor a raíz de su éxito masivo y lo ameno de su lectura- ${ }^{10}$ ya que a pocos autores en lengua castellana Pizarnik pondera de tal forma.

El caso de Djuna Barnes y su novela Nightwood (El bosque de la noche) entra, en mi opinión, en una variante opuesta. Entre el 24 y el 30 de agosto de 1969 Alejandra manifiesta en los Diarios una fascinación tan intensa por la escritora estadounidense que casi obliga a Silvina Ocampo -de quien en ese momento está fatalmen-

${ }^{9}$ Se refiere a Cien años de soledad.

${ }^{10}$ Cuando hablo de la actitud despectiva hacia García Márquez, pienso, por ejemplo, en los pronunciamientos de Damián Tabarovsky en la entrevista "Contra el mainstream literario" publicada en la revista mexicana Replicante http://revistareplicante.com/, quien dice algo que diversos intelectuales argentinos suscriben: "Bueno, a mí la literatura que dio el boom literario de la década de los sesenta no me interesa. Por supuesto que hay tantas cosas metidas dentro de la bolsa de lo que fue el boom que habría que separar la paja del trigo: se metía en el boom a escritores antagónicos, Onetti y García Márquez son mundos opuestos. Así es que también es un poco injusto hablar del boom; no obstante, una parte importante de lo que uno podría decir literatura de dictadores, realismo mágico y otra clase de realismos, cierta novela urbana muy convencional, cierta idea del escritor que triunfa en París, todo eso me repugna”. 
te enamorada- a que la lea y, más significativo aún, llega a enviarle una carta el 13 de noviembre de ese mismo año, según se ve aquí:

Escribí una carta a Djuna. Parece un tanto forzada. No es para menos: yo hablo a una Djuna de 76 acerca de mi amor por una Djuna de 46. ¿Cómo no va a sentir celos de la que fue? ¿Cómo no va a sentir su vejez como un insulto? (Pizarnik, 2013: 912).

Si conjeturo que se puede entender como el caso opuesto al de García Márquez se debe a que, hasta el día de hoy, Djuna Barnes es considerada una escritora de culto, que sólo conocen los lectores y escritores muy exquisitos y libres de prejuicios -el prólogo al libro lo escribió T.S. Eliot en los años 30 y es una de las primeras novelas abiertamente lesbianas de la literatura estadounidense- y tal vez la editora quiso preservar ese conocimiento restringido y elitista. Aunque, en realidad, es una osadía de mí parte afirmarlo: en sus inclusiones y exclusiones Becciú se maneja por criterios para mí indescifrables.

\section{Del Sombrerero Loco como editor}

Precisamente esos criterios silenciados y esas decisiones tomadas son los que me llevan al punto siguiente. Me refiero a ciertos errores de edición que no sólo persisten sino que se agravan de una publicación a la otra; como ejemplo, señalo que quien sólo acceda a la nueva edición desconocerá todas las notas de la primera. Esta supresión aumenta el desconcierto que, en su momento, causó la primera edición entre los lectores no argentinos ante la "sopa de letras" -según la llamó una crítica española- ${ }^{11}$ que había en los Diarios. Porque Pizarnik casi infaliblemente ponía sólo las iniciales

${ }^{11}$ Me refiero al artículo de Ana Nuńo "Esperando a Alejandra" citado en la bibliografía. 
de las personas de su entorno y, si bien en la primera edición Becciú aclaraba por nota sólo algunas -cosa que se le criticó y que la cuidadosa traductora al francés, Anne Picard, palió en buena medida en la selección publicada en París (Pizarnik, 2010)-, al menos lo hacía. Pero en esta segunda edición, al desaparecer esas notas, el lector no argentino se queda todavía más desconcertado que diez años atrás. Además, argentinos e hispanohablantes compartirán en pie de igualdad el desconcierto -o la estupefacción- al advertir que, tras la entrada del 25 de abril de 1961 que cierra el Cuaderno de octubre de 1960 a 1961 (Pizarnik, 2013: 356-408) se pase al Cuaderno de mayo a agosto de 1962. Esto implica que falta el Cuaderno que cubriría 1961-1962, al que sin embargo Becciú alude explícitamente en la nota 32 al último párrafo de dicha entrada y que aparece en la página 1097 (según el criterio anglosajón las notas están al final del libro, lo que, sumado a sus mil cien páginas, hace singularmente incómoda su lectura). Sin embargo, como casi todas las entradas de ese período aparecen en el Apéndice IV 1961-1962, deducimos que, contra lo afirmado por Becciú en la nota, dicho "cuaderno" no existe como tal, en el sentido de contarse entre los cuadernos o libretas troncales, sino que se trata de uno de los legajos incluidos en los Apéndices. En efecto, seguramente es ese "texto mecanografiado de 32 hojas grapadas y con correcciones a mano de la autora" (Pizarnik, 2013: 1100), tal como la editora lo caracteriza en la nota 9 al Apéndice IV, sólo que sin establecer ninguna vinculación con el "cuaderno" de la nota 32.

Al margen de estos y otros defectos de edición -el criterio de ordenamiento de los cuadernos y los legajos, que convierte la lectura en un quebradero de cabeza; las insuficientes explicaciones acerca de la procedencia del material y su grado de integridad-por los cuales me atrevo a considerar la tarea de Becciú digna del Sombrerero Loco de Alice in Wonderland. Para mí el error más grave de todos es que quienes estudian la obra de Alejandra Pizarnik 
desde hace décadas, sólo pudieron saber en noviembre de 2013 y tras llegar a la página 991 de la edición que, además de una gran escritora, Alejandra Pizarnik era una adolescente prodigio o, tal vez, una esquizofrénica precoz. ${ }^{12}$

Porque si, como lo señala Becciú en "Acerca de esta edición", la editorial le puso un tope de páginas para la primera edición -“...se han incorporado un gran número de entradas, que antes, por razones de espacio, no habían podido incluirse" (Pizarnik, 2013:12)-, es improbable que le indicara qué material seleccionar. Es decir que fue responsabilidad suya no incluir, y en lugar privilegiado, lo que aquí aparece en el Apéndice I bajo el título "Verano de 1950" -es decir, cuando la autora tenía apenas 14 años- y que es una de las reflexiones más tremendas que haya escrito la poeta sobre la conciencia de la división del sujeto y de la inutilidad de la vida. Como es imposible transcribir todo el texto, he seleccionado unos pocos párrafos para que midamos la excepcional agudeza mental de esa adolescente:

Ella no teme la muerte. Sabe que "la otra” no morirá. Es más aún: morir significaría tal vez -y ésta es su esperanza- incorporarse a sí misma, abrazarse sin miedo, atreverse a abrir los ojos y mirarse. Mirarse por vez primera. Por eso quiere morir... (990).

${ }^{12}$ Si bien no tengo autoridad ni preparación para diagnosticar ninguna enfermedad mental, es un dato conocido de la bibliografía psiquiátrica que los brotes esquizofrénicos se producen normalmente en torno de los 16/17 años (Ver A. Pacheco \& H. Raventós, "Genética de la esquizofrenia: avances en el estudio de genes candidatos", Biología Tropical v.52 n.3, 2004). Sin embargo, esta idea -que algunos lectores han manifestado al leer los fragmentos de 1950, por lo cual la cito-, para el doctor Leonardo Leibson, psiquiatra y psicoanalista argentino que conoce bien el perfil subjetivo de Pizarnik pues lo ha trabajado -como se verá en la bibliografía-, no es acertada, ya que se trata de una interrogación sobre la identidad habitual en los adolescentes, sólo que su nivel de lucidez y su formulación resultan poco comunes. A este respecto, sin embargo, más adelante haré algunas consideraciones importantes. 
Ella se ama porque tiene miedo de odiarse. Hay algunos días -si bien son muy pocos- en los que se confiesa su odio. Pero esos días sufre como una herida abierta. [...] Por eso va delante de sí misma y se agasaja y se halaga, temerosa siempre de no haber hecho lo suficiente para complacerse... (991).

Pero sobre todo creer en la propia inutilidad. No apasionarse por nada propio ni ajeno. [...] Conocer que la esperanza es una mentira, que lo absoluto en la única aspiración legítima y que es inalcanzable. [...] Negar a la esperanza, a la espera y al sol. Agonizar con los ojos cerrados, sin apelación (992).

Si lo considero una postergación imperdonable se debe a que si hay una figura que atraviesa toda la obra pizarnikiana es la del doble, esa "otra" que literalmente estalla sumiendo a los lectores en un vértigo de de-subjetivación en la segunda estrofa de su poema "Extracción de la piedra de locura":

Hablo como en mí se habla. No mi voz obstinada en parecer una voz humana sino la otra que atestigua que no he cesado de morar en el bosque. Si vieras a la que sin ti duerme en un jardín en ruinas en la memoria. Allí yo, ebria de mil muertes, hablo de mí conmigo sólo por saber si es verdad que estoy debajo de la hierba. No sé los nombres. ¿A quién le dirás que no sabes? Te deseas otra. La otra que eres se desea otra. ¿Qué pasa en la verde alameda? Pasa que no es verde y ni siquiera hay una alameda. $\mathrm{Y}$ ahora juegas a ser esclava para ocultar tu corona ¿otorgada por quién?, ¿quién te ha ungido?, ¿quién te ha consagrado? El invisible pueblo de la memoria más vieja. Perdida por propio designio, has renunciado a tu reino por las cenizas. Quién te hace doler te recuerda antiguos homenajes. No obstante, lloras funestamente y evocas tu locura y hasta quisieras extraerla de ti como si fuese una piedra, a ella, tu solo privilegio (Pizarnik, 1968: 49-50). ${ }^{13}$

${ }^{13}$ Cuando cuento con las primeras ediciones de su obra, prefiero citar por ellas. 
Pero en este punto, y sobre todo en relación con la escritura de dichos párrafos, no podemos dejar de lado la advertencia que hace Mariana Di Ció acerca de la "mise au net" por parte de Pizarnik de gran parte de sus diarios con un criterio antológico (Di Ció, 2014: 53). Si bien Di Ció no se refiere específicamente a este Apéndice I, las notas que incorpora Becciú -sin ninguna alusión explícita a una reescritura, sin embargo (Pizarnik, 2013: 1099; notas 1, 2 y 3) - nos permiten suponer que años después la poeta puso en "escritura literaria" lo experimentado en ese momento de la adolescencia. Pero se trata sólo de suposiciones a posteriori que, sin duda, la editora podría haber explicado o haber mencionado en caso de no saberlo tampoco ella. Es importante señalar, también, que en estos escritos de sus catorce ańos aparece la primera mención al suicidio recogida en sus papeles.

\section{4. (Des)figuraciones de autor}

Para quienes están atentos a las perspectivas que la crítica adopta a la hora de abordar la obra de un creador, el concepto de "figura de autor" (Premat), "imagen de autor" (Gramuglio), "figuración autoral” (Premat) o "autofiguración” (Amícola) según sus diversas denominaciones, es una de las nociones más decisivas que se han elaborado en las últimas décadas para dar cuenta de la peculiar proyección de sí que los escritores construyen sobre el escenario literario y social a partir de su escritura. Al respecto Julio Premat advierte:

La identidad de un autor estaría caracterizada por la presencia simultánea de imperativos contradictorios [...] contradicciones que conllevan la necesidad, a cada paso de un carrera literaria, de afianzar y reconstruir el "ser escritor". Estas tensiones van a procesarse según estrategias diversas; por ello, y paradigmáticamente, las ficciones de autor, en tanto que relato, y las figuras de autor, en tanto que imagen, son espacios privilegiados para proponer solu- 
ciones dinámicas. Así, el acto de escritura puede verse como una "puesta en intriga" de la identidad, según la expresión de Ricoeur: se construye un relato pero también una coherencia, una dialéctica identitaria del que escribe (Premat, 2009: 12).

En consecuencia, al intentar visualizar las prácticas discursivas que intervienen en la construcción de una figura de autor, resulta notoria la necesidad de leer las ramificaciones de la noción foucaultiana de "función-autor", así como tomar en cuenta el concepto de "imagen de escritor" elaborado por María Teresa Gramuglio, que se refiere a la imagen propia que los escritores construyen en sus textos y en la que proyectan diversas representaciones de sí mismos, de su subjetividad y del modo en que piensan sus posiciones tanto dentro de la institución literaria como de la sociedad, reuniendo "una ideología literaria y una ética de la escritura" (Gramuglio, 1992: 39); o el de "autofiguración" de Amícola (2008:14) en el cual no me detengo porque presenta coincidencias con los anteriores.

En el caso de Pizarnik, su cuidadosa construcción del "personaje alejandrino" como figura de autor se va afianzando durante su estadía en París y se proyecta a la vez en sus libros a partir de 1962 -cuando publica Árbol de Diana- y en el escenario social, sobre todo a su vuelta de París. Al respecto, señalo que si bien lo venía elaborando desde la adolescencia, lo perfeccionó durante su etapa parisina, como lo vemos con mucha más claridad en la nueva edición de los Diarios y sus largas páginas consagradas a esos años, por más que ya se advertía en la primera edición y lo señalaba en mi biografía (Piña, 1991: 33-39 y 105-122). Este personaje es una "cartografía" ${ }^{14}$ del "poeta maldito" que la poeta va realizando desde

${ }^{14}$ Utilizo el término en sentido deleuziano, para diferenciarlo de la mera copia del modelo a que alude el término "calco" utilizado como opuesto por DeleuzeGuattari (Deleuze/Guattari, 1988: 17-19). 
su adolescencia y perfeccionando cada vez más hasta su culminación en lo vital -el suicidio, al estilo Nerval- y en lo literario: el suicidio poético, al estilo Rimbaud, en el sentido de destruir la poética que ha ido elaborando a lo largo de los años. Ésta, basada en la sólida estructura de sus poemas -en verso o en prosa, largos o breves- y en una corrección incesante del lenguaje en busca de la perfección, se convierte en el carnaval de obscenidad y desestructuración que campea en sus textos de La bucanera de Pernambuco o Hilda la Polígrafa (Mackintosh, 2010: 510-513; Piña, 2012: 191 215; 2014: 175-186).

Desde esta perspectiva, los diarios son una de las prácticas discursivas privilegiadas donde se produce una confrontación entre lo proyectado sobre el escenario cultural y tanto la "verdad" del sujeto -en el sentido lacaniano de deseo inconsciente- como las instancias de elaboración de la imagen deliberadamente construida.

Si resulta tan productivo confrontar las dos ediciones de los Diarios de Pizarnik entre sí así como la segunda con lo que sigue inédito de sus papeles de Princeton, se debe a que nos permite obtener dos figuras de autor diferentes: por un lado, la que surge del manejo que hace la propia escritora de la autocensura, básicamente en relación con su sexualidad, aspecto que ya han analizado Fiona Mackintosh en su seminal artículo "Self-Censorship and New Voices in Pizarnik's Unpublished Manuscripts", publicado en 2010, es decir antes de la segunda edición de los Diarios, y el todavía en prensa de Patricio Ferrari "Auto-censura en los diarios parisinos de Alejandra Pizarnik: 'Diario 1960-1961' y 'Les Tiroirs de l'hiver"15 y que Di Ció menciona en la nota antes citada. Como ninguno de los dos primeros especialistas utiliza el concepto de figura de autor o de imagen de escritor y la Dra. Di Ció no se detiene espe-

${ }^{15}$ Presentado durante el Colóquio Internacional "Ilusión y materialidad de los archivos literários," organizado por Jerónimo Pizarro, en la Universidad de los Andes el 7 y 8 de mayo de 2014. 
cialmente en ella, me ha parecido interesante incluirla y analizarla en mi estudio; por otro lado, en una flexión no considerada por la crítica hasta el momento, la figuración autoral que traza la editora a partir de las exclusiones que realiza tanto en la primera como en la segunda edición.

Cuando se confrontan los "cuadernos centrales" de París -según los he llamado al comienzo de este artículo- con las reescrituras de Pizarnik incluidas en los Apéndices II, III y IV de la versión 2013 de los Diarios, queda clara la voluntad de la poeta de ocultar su homosexualidad a la hora de publicar fragmentos del diario. Esto resulta evidente en el ejemplo que seleccioné -uno entre muchos- que incluye las siguientes entradas; la redacción del párrafo final de una larga entrada de 1961 fechada el sábado 14-después deducimos que es del mes de enero- tal como aparece en el cuaderno central:

En cierto modo, es como si me obligara a sufrir por ella. En verdad no tengo ganas de verla ni me importa. Pero es como si debiera sufrir por ella. Como si lo más terrible de todo fuese quedar sin rostros concretos y reales, es decir, que mi nostalgia se limite a un sonido, un perfume. M. es un comodín en la historia de mi nostalgia. Lo que hace que me fascine está en mí, no en ella. Yo no la conozco. Es un nombre. Pero no comprendo por qué no me quiere, por qué no desea siquiera saludarme. Es que tal vez intuye algo de lo que sucede y le da miedo. Por otra parte, yo debo dar miedo. (Sería divertido si al final resulta que la que da miedo soy yo) (Pizarnik, 2013: 390).

Y la publicada con igual fecha dentro de "Fragmentos de un diario" -incluido en el Apéndice III, Les Tiroirs de l'hiver- en la revista colombiana Mito número 39-40 de 1962, la cual queda reducida a lo siguiente:

Como si debiera sufrir por él. En verdad no quiero verlo ni me importa. Pero es como si debiera sufrir por él, como si lo terrible 
fuera quedar sin rostros concretos y reales y que mi nostalgia se limite a un sonido, a un perfume (Pizarnik, 2013: 1053).

Es casi innecesario señalar que si en la primera entrada la reflexión se refiere a una mujer, en la segunda se la ha travestido de hombre; en consecuencia, tanto como las correcciones de estilo y la condensación demuestran la voluntad literaria de Pizarnik, la mutación genérica tiende a construir una autofiguración heterosexual. ${ }^{16}$

Acerca de la figuración autoral que construye Becciú en la primera edición por comparación con la segunda, la serie de exclusiones que practicó y que parcialmente he señalado antes, proyectan una imagen de escritora mucho menos transgresora y terrible que la trazada por la segunda -donde a la bisexualidad, la participación en orgías sexuales y la falta de lealtad con diversas amigas, se suma el patetismo de su amor no correspondido por Silvina Ocampo, del que sólo se supo por la Correspondencia Pizarnik editada por Ivonne Bordelois en 1998-, pero también más reducida en sus intereses literarios, según se apuntó. Asimismo -cosa que apenas puedo señalar al pasar porque su análisis implicaría otro artículo extenso- excluyó las referencias a la bulimia patológica que sufría la autora y redujo sustancialmente lo relativo a la también patológica relación amor-odio que mantenía con el Dr. Pichon-Rivière, su analista, y a su casi insoportable sufrimiento psíquico. Es decir que construyó una Alejandra mucho menos doliente, desequilibrada y patética -esa silenciada adolescente prodigio o esquizofrénica precoz que se convirtió en una mujer interiormente desgarrada- pero

${ }^{16}$ En el caso de Pizarnik considerarla homo o heterosexual es reduccionista, ya que en rigor elude la tradicional oposición binaria de la sexualidad a favor de la bisexualidad, posición que queda ampliamente demostrada en esta edición de los Diarios, así como en su obra, según lo he señalado en mi artículo. 
también menos poseída por la pasión de leer y de saber, y menos obsesionada por su tarea de escritura.

Quedaría, por fin, referirse a los fragmentos que se desecharon incluso en esta segunda edición y su repercusión en la imagen de escritora. Ya he dicho que en lo personal coincido con la decisión de la editora de no ahondar en los desgarramientos familiares elección que, tal vez, otros críticos, con todo derecho, encuentren censurable- para no añadir aspectos abismales a su figura, pero no me explico qué sentido tienen los súbitos pudores ante ciertas referencias sexuales, cuando se han incluido pasajes totalmente explícitos y las largas y estremecedoras páginas en las que la escritora habla sobre el dolor psíquico y físico que le produjo el aborto que debió practicarse en París. Tampoco, el silenciamiento de sus gustos musicales, entre los cuales, según palabras de su hermana Myriam ${ }^{17}$ Vivaldi ocupaba un lugar de privilegio y al que se lo ha excluido en más de una ocasión.

Por cierto que habría muchas cosas más que señalar, pero considero que he dado cuenta de los aspectos fundamentales que pone de manifiesto la confrontación entre las distintas ediciones y materiales inéditos. Estos nos enfrentan, al igual que la publicación en 2000 y 2002 de su supuesta obra completa en prosa y poesía, con la certidumbre de que todavía nos queda mucho por descubrir de su producción, la cual, en consecuencia seguirá siendo un objeto en constante mutación. Correlativamente, seguiremos siendo incapaces de captar los alcances de la figuración autoral que la poeta se propuso construir. ${ }^{18}$ Una edición crítica de sus Diarios es lo que todo lector de la obra de Pizarnik desea y merece.

${ }^{17}$ Dato aportado por Myriam Pizarnik de Nesis durante la serie de conversaciones realizadas en enero y febrero de 2016 en su domicilio.

${ }^{18}$ He dejado totalmente de lado, por cuestiones de espacio, lo que nos revelan los textos de la Dra. Nora Catelli sobre los Diarios, en especial, su artículo "Los Diarios: estrategias de lectura". En éste, la estudiosa explica que fue la primera 


\section{Bibliografía}

Amícola, José, 2008, Autobiografía como autofiguración. Estrategias discursivas del Yo y cuestiones de género, Rosario, Beatriz Viterbo.

Barnes, Djuna, 1961, Nightwood. New York: New Directions. [El bosque de la noche], Enrique Pezzoni (trad.), Caracas, Monte Ávila.

Blanchot, Maurice, 1992, El libro que vendrá, Pierre de Place (trad.), Caracas, Monte Ávila.

Bordelois, Ivonne, 1998, Correspondencia Pizarnik, Buenos Aires, Seix Barral.

Calafell Sala, Núria, 2011, "Los Diarios de Alejandra Pizarnik. Una escritura en el umbral", Castilla. Estudios de Literatura, núm.2, pp. 55-71

Catelli, Nora, 2002, "Invitados al palacio de las citas - Los diarios inéditos", Clarín Cultura y Nación, Buenos Aires, sábado 14 de septiembre, p. 5.

, 2007, En la era de la intimidad: seguido de El espacio autobiográfico, Rosario, Beatriz Viterbo Editora.

, 2013, "Los Diarios: estrategias de lectura", en Adelaïde de Chatellus y Milagros Ezquerro (eds.), Alejandra Pizarnik: el lu-

persona a quien le encargaron editar los Diarios de Pizarnik, tarea que se interrumpió por el desacuerdo radical con sus criterios de selección primero por parte de Aurora Bernárdez - en cuyo poder obraba la valija donde se le habían entregado a Julio Cortázar los Papeles Pizarnik-, después de Becciú y finalmente de la Agencia Balcells (Catelli, 2013: 142-143). Asimismo, su descubrimiento de la intrusión de otra mano ya en los Diarios que se le entregaron para su edición en 1997, a partir de la sospechosa titulación de Último cuaderno en la agenda que recoge entradas de 1970, 1971 y 1972 (Catelli, 2013: 143-144), precisamente la parte de los Diarios que Becciú excluye totalmente de su selección por su carácter "muy personal e íntimo" (Pizarnik, 2013: 13). A estas reflexiones habría que sumarles las de Mariana Di Ció antes señaladas. 
gar donde todo sucede, Coloquio Internacional Pizarnik de la Sorbonne, París, L'Harmattan, pp. 141-150.

Deleuze, Gilles y Félix Guattari, 1990, Mil mesetas. Capitalismo y esquizofrenia, Barcelona, Pre-textos.

Di Ció, Mariana, 2014, Une calligraphie des ombres. Les manuscrits d'Alejandra Piarnik, París, L'Harmattan.

Ferrari, Patricio, 2015, "Auto-censura en los diarios parisinos de Alejandra Pizarnik: 'Diario 1960-1961' y 'Les Tiroirs de l'hiver'", Illusion and Materiality of Literary Archives (Presentado en el Coloquio Internacional sobre la Ilusión y Materialidad de los Archivos Literarios - Los Andes, Bogotá, 7 y 8 de mayo de 2014. Fecha de publicación estimada: 2017).

Foucault, Michel, 1984, "Qué es un autor", Conjetural. núm. 4, agosto, pp. 87-11

Giordano, Alberto, 2006, "Digresiones sobre los diarios de escritores (Charles du Bos, entre Alejandra Pizarnik y Julio Ramón Ribeyro)", en Una posibilidad de vida. Escrituras intimas, Rosario, Beatriz Viterbo Editora, pp. 137-150.

Gramuglio, María Teresa, 1992, "La construcción de la imagen”, en Hector Tizón, Rodolfo Rabanal y María Teresa Gramuglio, La escritura argentina, Santa Fe, Ediciones Universidad Nacional del Litoral, pp. 37- 64.

Graziano, Frank (ed.), 1987, Alejandra Pizarnik. A Profile, Colorado, Logbridge Rhodes. , 1996, Semblanza, México, FCE.

Leibson, Leonardo, 2015, "La metáfora exacta. Alejandra Pizarnik, la poesía, el humor, la muerte", Psicoanálisis y el hospital, año 24, núm. 48, Noviembre, pp. 8-12.

Mackintosh, Fiona J., 2010, "Self-Censorship and New Voices in Pizarnik's Unpublished Manuscripts", Bulletin of Spanish Studies, vol. LXXXVII, núm. 4, pp. 509-535. 
Nuño, Ana, 2004, "Esperando a Alejandra - Diarios", en La Vanguardia Digital. Disponible en: http://www.lavanguardia.es/ web/20031231/51149330710.html (consultado: 6/I/2003).

Piña, Cristina, 1991, Alejandra Pizarnik. Una biografia, Buenos Aires, Planeta.

,2007, "Poder, escritura y edición. Algunas reflexiones acerca de la Poesía completa, la Prosa completa y los Diarios de Alejandra Pizarnik", Páginas de guarda. Revista de lenguaje, edición y cultura escrita. núm. 3, otoño, Argentina, pp. 61-77.

, 2012, Limites, diálogos, confrontaciones. Leer a Alejandra Pizarnik, Buenos Aires, Corregidor.

, 2013, "La profanación e inversión del proyecto narrativo", en Adelaïde de Chatellus y Milagros Ezquerro (eds.), Alejandra Pizarnik: el lugar donde todo sucede, Coloquio Internacional Pizarnik de la Sorbonne, París, L'Harmattan, pp. 175-186.

Pizarnik, Alejandra, 1960-1961, “Diario”, Mito, Jorge Gaitán Durán y Hernando Valencia Goelkel (dirs.), núm. 39-40, Bogotá, noviembre-diciembre, pp. 110-115.

, 1962, "Fragmentos de un Diario", en Poesía=Poesía, Roberto Juarroz (dir.), Buenos Aires, núm. 11-12-13, diciembre, p. 5.

, 1962, "Les Tiroirs de l'hiver", La Nouvelle Revue Française, Rédacteurs en chef Jean Paulhan et Marcel Arland, núm. 113, Paris, 1 de mayo, pp. 943-947.

, 1968, Extracción de la piedra de locura, Buenos Aires, Sudamericana.

, 2000, Poesía completa. (1955-1972), Ana Becciú (ed.), Barcelona, Lumen.

, 2002, Prosa completa, Ana Becciú (ed.), Ana Nuño (prol.), Barcelona, Lumen. 
, 2003, Diarios, Ana Becciú (ed. e intro.), Barcelona, Lumen.

, 2010, Journaux 1959-1971, Silvia Baron Supervielle, (ed.), Anne Picard (trad.), París, José Corti. , 2013, Diarios, Ana Becciú (ed.), Barcelona, Lumen.

Premat, Julio, 2009, Héroes sin atributos. Figuras de autor en la literatura argentina, Buenos Aires, FCE.

Rocco, Federica, 2012, "Los Diarios de Alejandra Pizarnik. Del desdoblameinto a la multiplicación del sujeto", en Arturo Donati, Emanuele Leonardi, Giovanna Minardi, Assunta Polizzi, En la otra orilla de la noche. En torno a la obra de Alejandra Pizanrik. Roma, ARACNE Editrice, pp. 137-152.

Tabarovsky, Damián, 2011, "Contra el mainstream literario", Replicante, México, noviembre. Disponible en: http://revistareplicante.com/ (consultado: 10/VI/2015).

Venti, Patricia, 2004, "Los diarios de Alejandra Pizarnik: censura y traición", Espéculo, núm. 26. Disponible en: http://www.ucm. es/info/especulo/numero 26/diariosp.html (consultado: 10/ IX/2014).

, 2008, "La escritura invisible. Diarios", en El discurso autobiográfico en Alejandra Pizarnik, Barcelona, Anthropos Editorial, pp. 37-60

Vrech, Carolina, 2013, "La escritura fragmentaria en los Diarios", en Adelaide de Chatellus y Milagros Ezquerro (eds.), Alejandra Pizarnik: el lugar donde todo sucede, Coloquio Internacional Pizarnik de la Sorbonne, París, L'Harmattan, pp. 151-163. 